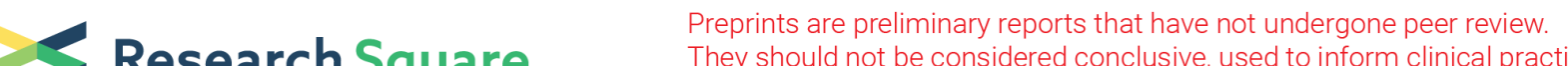 Research Square They should not be considered conclusive, used to inform clinical practice, or referenced by the media as validated information.
}

\section{The role of reducing incision complications of surgical techniques used in groin lymphadenectomy for Vulval Malignancies}

\section{Xiao Ling Zhang}

1.School of Medicine, Shandong University;2. Shandong Cancer Hospital and Institute xiugui Sheng ( $\sim$ Shengxiugui@163.com )

Shandong Tumor Hospital and Institute

Naifu Liu

Shandong Cancer Hospital and Institute

Jinlong Chen

Shandong cancer hospital and institute

\section{Tingting Zhang}

shandong cancer hospital and institute

\section{Fufeng Gao}

shandong cancer hospital and institute

\section{Research}

Keywords: Vulval Malignancy, Surgery, Negative drain technique, Complication, Inguinal lymphadenectomy

Posted Date: April 12th, 2020

DOI: https://doi.org/10.21203/rs.3.rs-18894/v1

License: (c) (i) This work is licensed under a Creative Commons Attribution 4.0 International License. Read Full License 


\section{Abstract}

\section{Background}

Inguinal lymphadenectomy plays an important role in the cure of patients with inguinal metastasis from vulval cancer or prophylactic inguinal lymphadenectomy.Unfortunately, this treatment is often associated with multiple postoperative complications. This work set out to investigate the efficacy and tolerance of negative pressure without subcuticular suture versus routine manipulation after inguinal lymphadenectomy for patients with vulval malignancies

\section{Methods}

75 patients with vulval malignancies were allocated into two groups depending on their clinical stages, with one of them (38 patients included, A group) being subjected to negative pressure drainage without subcuticular suture and the other (37 patients included, B group) to routine drainage with subcuticular suture after treated with inguinal lymphadenectomy. The operative time, seroma, hematoma, hemorrhage, wound infection, skin flap necrosis, were selected as the monitored parameters, through which the above two groups were compared with each other using t test, $c 2$ analysis.

\section{Results}

(1) The median operative time for unilateral inguinal lymphadenectomy was $49 \min (33 \min \otimes 70 \mathrm{~min})$ in $\mathrm{A}$ group, compared to $63 \mathrm{~min}(50 \otimes 85 \mathrm{~min})$ in $B$ group $(P<0.01)$, and it was $3 \mathrm{~min}(2.5 \mathrm{~min} \otimes 5 \mathrm{~min}) 12.5 \mathrm{~min}(7 \rrbracket$ $15 \mathrm{~min})$ for only incision closing time(Pख0.01). It was $11.7 \mathrm{~d}$ of the flap healing time in A group and $20.9 \mathrm{~d}$ in B group. Further, the time(d) of antibiotics usage was still different, $3 \mathrm{~d}$ and $5.5 \mathrm{~d}$. (2) Short-term lower extremity lymphedema occurred with 18 patients (31.6\%) in the A group and 24 patients $(44.4 \%)$ in the B group ( $P>0.05)$. Still, flap necrosis was observed with 26 patients (10.5\%) in A group while 11developed $(20.4 \%)$ in $B$ group $(P<0.05)$, and the incision infection was observed in $4(7 \%)$ patient in $A$ group instead of $16(29.6 \%$ ) in B group (Pख0.01). However, there was no statistical difference in postoperative fever, acute cellulites, seroma, or lymphocyst formation. (3) Discomfort occurrence rate decreased by about $50 \%$ in patients subjected to study group compared with those to control group, while there was no remarkable difference between two groups in the occurrence rates of drain block $(P>0.05)$.

\section{Conclusion}

The application of negative drain technique during inguinal lymphadenectomy for patients with vulval malignancies could result in significant decrease in the occurrence of postoperative complications and good tolerance, and should be widely put into clinical practice.

\section{Background}

Inguinal lymphadenectomy plays an important role in the cure of patients with inguinal metastasis from vulval cancer or prophylactic inguinal lymphadenectomy. Unfortunately, this treatment is often 
associated with multiple postoperative complications usually classified into minor-wound infection, seroma formation requiring drainage, skin necrosis, low extremity pain, and sense abnormity, and majordeep venous thrombosis, persistent seroma formation, flap necrosis requiring skin graft, low extremity cellulitis, and permanent and disabling leg lymphedema, each of them leading to a significant decrease in the patient's survival quality. The postoperative morbidity to both body image and function make this issue worthy of careful consideration.

Though many changes has been done to reduce the complications, such as saphenous vein preservation technique which has reduced the complications significantly ${ }^{[1]}$, still more work needed to enhance patients survival quality. Lymphadenectomy associated with drainage has been reported to promote wound healing, and of course the continuous improvement of the technique was studied ${ }^{[2]}$. In breast cancer, the postoperative management after axillary lymphadenectomy has been studied in more detail ${ }^{[3]}$, which can be referred during inguinal lymphadenectomy for patients with vulval carcinoma.

Herein, we presented our experience with negative pressure drainage without subcuticular suture after inguinal lymphadenectomy for patients with vulval carcinoma. The results of 38 patients treated in this manner are reported.

\section{Materials And Methods \\ Patient's information}

There were 75 patients with vulval malignancies enrolled in our hospital from Jan of 2013 to Dec of 2019 , who were performed to radical vulvectomy/radical local excition combined with bilateral/unilateral inguinal lymphadenectomy using separate groin incisions. These 75 patients were from 36 to 75 years old with the median age being 67 , and 51 of them were more than 60 years old. The distribution of FIGO (2009) stage for the 75 cases said above was as follows: 18 in stage $\rrbracket, 39$ in stage $\rrbracket, 17$ in stage $\varangle, 1$ in stage $\varangle$, and 8 of them were referred from outside institutions, according to the method of random number table they were divided into two groups, and their characteristics were listed in Table 1.

Table 1 The median age(years), clinical stages, pathological types

\begin{tabular}{cccccccccc}
\hline Group & Age & \multicolumn{3}{c}{ Clinical stage } & \multicolumn{3}{c}{ Pathological type* } \\
\cline { 3 - 9 } & & & $\square$ & $\square$ & & SCC & MM & BCC \\
\hline A & 67 & 9 & 19 & 10 & 0 & 35 & 3 & 0 \\
B & 66.5 & 9 & 20 & 7 & 1 & 34 & 2 & 1 \\
\hline
\end{tabular}

*:SCC, squamous cell carcinoma; MM, malignant melanoma; BCC, basal cell carcinoma.

There were no significant difference on the median age, clinical stages and pathological types between the two groups by statistic analysis, $\mathrm{P}>0.05$. 
The patients presented the typical symptoms of a long history of pruritus and local pain with a vulvar lump, even bleeding, the most common signs of vulvar cancer. The time of symptom presenting before diagnosis ranged from 6 months to 10 years with the median value of 2 years.

Inclusion criteria: informed consent of patients and their families; no severe organ dysfunction; patients have good tolerance to operation; the agreement of Hospital Ethics Committees(HECs).

Exclusion criteria: with serious autoimmune disease; with psychiatric disorders.

Chronic lymphocysts and chronic lymphedema were defined as occurring or persisting more than 30 days postoperatively.

Criteria of incision infection: incision redness, swelling, fever and pain; incision necrosis, massive purulent exudation.

\section{Pathology}

The diagnosis is only based on pathology. 75 patients were all histologically proven before treatment (histopathological reports of cases treated in other hospital initially were reviewed and confirmed in our hospital). 69 were squamous cell carcinoma, 5 were malignant melanoma, 1 were basal cell carcinoma. And, $67 \%(50 / 75)$ also suffered from malnutrition disease.

\section{Operation Technique}

Vulvar cancer is usually treated with surgery, whose procedure depends closely on the size, depth, and the lymph status. Radical vulvectomy combined with bilateral inguinal sentinel lymphadenectomy was employed in 6 cases, and local radical vulvectomy with unilateral inguinal lymphadenectomy in 15 patients, while local radical vulvectomy with sentinel lymphadenectomy was performed in 7 , howerver the left 47 patients were delivered radical vulvectomy with bilateral inguinal lymphadenectomy. There is no difference between the two groups in the operation manner distribution by statistic. Total 111 groins were delivered inguinal sentinel lymphadenectomy/lymphadenectomy for 75 patients(57 in A group, 54 in B group). The flat drains were placed in the 38 cases groin operation area Fr18(6-mm) drains (Shan Dong Bei Rui Si medical device company)(Fig. A), which were secured with a 4-silk suture on the lowest point and connected with the bulb(200 ml, the negative produced about $15 \mathrm{kPa})$ section(Fig. B), then the drainage output was monitored daily by nursing staff, and the drains were removed when the output was less than $10 \mathrm{ml}$ per 24 hours, on the other hand the routine was performed in the other 37 patients( B group). There is another important difference between the two groups, subcuticular suture for wound closure was not being taken in negative suck group instead of Scarpa's fascia being interrupted suture to the skin in routine group, during which the skin and subcutaneous tissue could be better fitted, and then the skin was sutured by stapels. The lymph nodes and adipose tissue were removed by ultrasonic scalpel 
in two group patients which supposed could be reduce the formation of lymphocysts, during which both the electrocogulation and suture were used for stop bleeding.

\section{Follow-up And Statistics Method}

The patients were followed up by reexamination in the ambulant clinic, WeChat and telephone. Up to Dec of 2019, there were only three patients lost in A group and four lost in B group with the follow-up rates amounting to $92.1 \%$ and $89.2 \%$, respectively. Of the seven patients lost, 3 of them were out of contact, the other 4 did not make any response to the follow-up. Statistical analysis was performed with SPSS 19.0. The operating time, wound healing, seroma, hematoma, hemorrhage, wound infection, skin flap necrosis were selected as monitored parameters, through which the two groups were compared with each other using $t$ test, $\chi^{2}$ test. An alpha value of 0.05 was used in all statistical analyses, and $p$ values less than 0.05 were considered statistically significant.

\section{Results}

\section{Operative Time Duration Of Inguinal Lymphadenectomy}

The median operative time for unilateral inguinal lymphadenectomy was $49 \min (33 \min \varangle 70 \min$ ) in A group, similar to that in B group, $63 \mathrm{~min}(50 \rrbracket 85 \mathrm{~min})(P \llbracket 0.01)$, and the mean incision closing time was 3 min for A group, however 12.5 for $B$ group(Pख0.01), and there is a significant difference.

\section{Wound Healing}

Criteria of incision healing: i : Good incision healing; ii: Poor incision healing, no abscess; iii: incisional pus.

Primary wound healing time was noted in 34 (89.5)\% in A group vs 22 (59.5)\% in B group(Pख0.05).The mean healing time was $11.7 \mathrm{~d}$ in A group compared to $20.9 \mathrm{~d}$ in B group, and the significant difference of the results was seen between the two groups.

\section{Hospital Stay And Antibiotics Usage}

The average length of stay was 13.5 day in A group, while 22 in B group, and the mean time of antibiotics usage was 3 day in A group instead of 5.5 in B group, and the difference between them was significant by statistics.

The comparison of time in between two group was seen in Table 2. 
Table 2

The comparison of time

\begin{tabular}{|c|c|c|c|c|c|}
\hline \multirow[t]{2}{*}{ Group } & \multicolumn{2}{|l|}{ Operatin time } & \multirow{2}{*}{$\begin{array}{l}\text { Flap healing } \\
\text { time(d) }\end{array}$} & \multirow{2}{*}{$\begin{array}{l}\text { Average length of } \\
\text { stay(d) }\end{array}$} & \multirow{2}{*}{$\begin{array}{l}\text { time of } \\
\text { antibiotics } \\
\text { Usage(d) }\end{array}$} \\
\hline & $\begin{array}{l}\text { Total operation } \\
\text { time(m) }\end{array}$ & $\begin{array}{l}\text { Incision closing } \\
\text { time(m) }\end{array}$ & & & \\
\hline A & $\begin{array}{l}49 \\
(n=57)\end{array}$ & $\begin{array}{l}3 \\
(n=57)\end{array}$ & $\begin{array}{l}11.7 \\
(n=57)\end{array}$ & $\begin{array}{l}13.5 \\
(n=38)\end{array}$ & $\begin{array}{l}3 \\
(n=38)\end{array}$ \\
\hline B & $\begin{array}{l}63 \\
(n=54)\end{array}$ & $\begin{array}{l}12.5 \\
(n=54)\end{array}$ & $\begin{array}{l}20.9 \\
(n=54)\end{array}$ & $\begin{array}{l}22 \\
(n=38)\end{array}$ & $\begin{array}{l}5.5 \\
(n=38)\end{array}$ \\
\hline $\mathrm{T}$ & -4.862 & -20.732 & -6.822 & -6.498 & -7.151 \\
\hline$P$ & 0.000 & 0.000 & 0.000 & 0.000 & 0.000 \\
\hline
\end{tabular}

\section{Acute Complications}

Short-term lower extremity lymphedema occurred with 18 groins (31.6\%) in the A group and 24 groins $(44.4 \%)$ in the B group $(P>0.05)$. Still, flap necrosis was observed with 6 groins $(10.5 \%)$ in $A$ group while $11(20.4 \%)$ in $B$ group $(P>0.05)$. While, incision infection happened less frequent in $A$ group $(7 \%, 4 / 57)$ vs $(29.6 \%, 16 / 54)$ in B group. The occurrence rates of discomfort of drainage decreased by about $50 \%$. However, there was no statistical difference in drain block, acute cellulites, seroma, or lymphocyst formation (Table 3). The puncture would be performed if the lymphocyst larger more than $2 \mathrm{~cm}$ for patients with lymphoceles. 
Table 3

The comparison of incision complications of the 2 groups

\begin{tabular}{|lllll|}
\hline Group & A & B & $\mathbf{c}^{2}$ & $\boldsymbol{P}$ \\
\hline Seroma & $\begin{array}{l}24.6 \% \\
(14 / 57)\end{array}$ & $\begin{array}{l}22 \% \\
(12 / 54)\end{array}$ & 0.084 & 0.771 \\
\hline Flap necrosis & $\begin{array}{l}10.5 \% \\
(6 / 57)\end{array}$ & $\begin{array}{l}20.4 \% \\
(11 / 54)\end{array}$ & 2.071 & 0.150 \\
\hline Incision infection & $\begin{array}{l}7 \% \\
(4 / 57)\end{array}$ & $\begin{array}{l}29.6 \% \\
(16 / 54)\end{array}$ & 9.598 & 0.002 \\
\hline Lower extremity edma & $\begin{array}{l}31.6 \% \\
(18 / 57)\end{array}$ & $\begin{array}{l}44.4 \% \% \\
(24 / 54)\end{array}$ & 1.951 & 0.162 \\
\hline Drain block & $\begin{array}{l}12.3 \% \\
(7 / 57)\end{array}$ & $\begin{array}{l}14.5 \% \\
(8 / 54)\end{array}$ & 0.153 & 0.696 \\
\hline discomfort of drainage & $\begin{array}{l}22.2 \% \\
(12 / 57)\end{array}$ & $\begin{array}{l}40.7 \% \\
(22 / 54)\end{array}$ & 5.059 & 0.025 \\
\hline
\end{tabular}

\section{Chronic Complications}

According to the results shown in Table 3 , it is easy to find out that long-term complications such as sense abnormity, lower extremity pain were less frequent for patients in study group compared to those in control group though there is no statistic difference, but there was no remarkable difference between two groups in the occurrence rates of lower extremity lymphedema, phlebitis and deep venous thrombosis. The reason why chronic lower extremity lymphedema is similiar between two groups may be the compensatory effect of great saphenous vein, since saphenous vein were both spared in two groups. The comparison of chronic complications of the 2 groups were shown in Table 4.

Table 4

The comparison of chronic complications of the 2 groups

\begin{tabular}{|llllll|}
\hline Group & $\begin{array}{l}\text { Lower } \\
\text { extremity edma }\end{array}$ & $\begin{array}{l}\text { Lower } \\
\text { extremity pain }\end{array}$ & $\begin{array}{l}\text { Lower extremity } \\
\text { phlebitis }\end{array}$ & $\begin{array}{l}\text { Deep venous } \\
\text { thrombosis }\end{array}$ & $\begin{array}{l}\text { Sense } \\
\text { abnormity }\end{array}$ \\
\hline A & $\begin{array}{l}27.8 \% \\
(15 / 57)\end{array}$ & $\begin{array}{l}19.3 \% \\
(11 / 57)\end{array}$ & $\begin{array}{l}3.5 \% \\
(2 / 57)\end{array}$ & $\begin{array}{l}5.3 \% \\
(3 / 57)\end{array}$ & $\begin{array}{l}14 \% \\
(8 / 57)\end{array}$ \\
\hline B & $\begin{array}{l}31.5 \% \\
(17 / 54)\end{array}$ & $\begin{array}{l}31.5 \% \\
(17 / 54)\end{array}$ & $\begin{array}{l}1.9 \% \\
(1 / 54)\end{array}$ & $\begin{array}{l}7.4 \% \\
(4 / 54)\end{array}$ & $\begin{array}{l}24.1 \% \\
(13 / 54)\end{array}$ \\
\hline$\chi^{2}$ & 0.360 & 2.182 & 0.290 & 0.216 & 1.822 \\
\hline$P$ & 0.548 & 0.140 & 0.591 & 0.642 & 0.177 \\
\hline
\end{tabular}




\section{5-year Survival Rate And Recurrence}

5-year survival rate was calculated using the lifetable $71.2 \%$ for overall cases, and there was no statistical difference between two groups $(P>0.05)$. Followed up to June of 2019,7 groins $(6.3 \%)$ suffered recurrence in all patients. The local recurrence is the most frequency for treatment failure, and usually can be treated successfully if diagnosed early.

\section{Discussion}

Incidence of vulvar cancer has been increasing by an average of $4.6 \%$ every 5 years, which caused 1200 deaths in 2018, and 6190 new cases are estimated to occur every year ${ }^{[4,5]}$

The primary therapeutic approach to cure vulval malignancies is surgery, while subcutaneous effusion after the operation, which often induce infection and delayed healing of wound. Accordingly, many patients will still continue to suffer from persist lower extremity lymphedema in the future. Gould $\mathrm{N}$ ${ }^{[8}$ found that early postoperative cellulitis (<30 days after surgery) developed in $35.4 \%$, early wound breakdown in $19.4 \%$, early lymphedema in $4.8 \%$, and early lymphocyst formation in $13.1 \%$. Late cellulitis (> 30 days after surgery) developed in $22.2 \%$, late wound breakdown in $3.2 \%$, late lymphedema in $29.5 \%$, and late lymphocysts in $5 \%$. The surgical treatment of vulvar cancer has evolved significantly over the past century to reduce the complication morbidity. Less radical modifications were formulated by Hacker, who promoted separate groin incisions in 1981, sparing the intervening skin bridge between the groins and the vulva $^{[6]}$, for groin node evaluations, the requirement to perform routine groin lymphadenectomies for all vulvar cancers was modified after findings from a 1987 GOG study ${ }^{[7]}$, for tumors with $>1 \mathrm{~mm}$ invasion and that are up to $4 \mathrm{~cm}$ in size can be accomplished with either sentinel lymph node (SLN) biopsies, or IFLNDs, since two prospective multicenter studies, GOG 173 and GROINSS-V-1, have demonstrated the safety and feasibility of SLN mapping of the groin in vulvar cancer ${ }^{[15,16]}$.

There is no consensus in the literature on the association between the use of suction drainage and complications arising from groin node dissection. Gould et al ${ }^{[8]}$ found no association between duration of suction usage and complications, whereas Walker KF

et $a^{[2]}$ found that a short duration of use was associated with high rates of wound breakdown and a long duration of use was associated with higher rates of lymphedema, and recommend the use of subcuticular suture for wound closure. Pontre $\mathrm{J}^{[9]}$ advocated that Compared with patients in whom inguinal drains were placed, those in the "no drain" group had a significantly lower incidence of postoperative groin cellulitis ( $8.7 \%$ vs $25.4 \% \mathrm{P}=0.039)$. No significant differences were observed between patients in the "drain" and "no drain" groups in lymphocyst formation, wound infection, duration of hospital stay, and lower-limb lymphedema. However, our data show that Short-term lower extremity lymphedema occurred less frequency $(31.6 \%)$ in the A group than B group (44.4\%) $(P>0.05)$, also flap necrosis was observed in $10.5 \%$ groins for $A$ group instead of $20.4 \%$ for $B$ group $(P<0.01)$, and further incision infection happened more often in B group (29.6\%) vs (7\%). However, there was no statistical 
difference in acute cellulites, seroma, lymphocyst formation, or chronic lower extremity edma. It is worth mentioning that the occurrence rates of discomfort of drainage decreased by about $50 \%$ in our study $(\mathrm{P}<$ 0.05).

It is concluded from many research results that if negative drain was placed in the wound for patients with operation, multiple postoperative, especially incision complications will be relieved to a different extent ${ }^{[10]}$.

This operative modality has been employed in our hospital since 2013 , and negative drain without subcuticula suture was carried out in $\mathbf{5 7}$ groins by now. It is worth noting that there was an observable decrease in short-term complications, such as wound broke down, necrosis, infection as well as long-term complications including sense abnormity and pain.

Walker $\mathrm{KF}^{[2]}$ recommended the use of a subcuticular continuous suture for skin closure which was recognized a lower risk of lymphocyst formation and lymphedema than the use of staples. However, we come to the opposite conclusion, since the manipulation of no subcutaneous suture contributed to not only flap well matched but also reduce flap tension, which relieved the wound broken, furthermore the negative drainage can facilitated tight fit between skin and deep tissue without cavity left, and then promote wound adhesion and the elimination of effusion, and at the same time a big difference was observed with the wound closing time. Carlson et al ${ }^{[14]}$ found an increased risk of short-term cellulitis with suction drain usage, but there was no significant difference between two groups on those aspects in our study, likely due to some methods performed on both groups as follows. First, the application of ultrasonic scalpel in inguinal lymph node dissection reduced the formation of two groups of lymphocysts. Secondly, the usage of staples reduced the inflammatory response of the flap. Furthermore, wound infrared ray therapy twice a day and vigorous care to keep the wounds clean and dry almost always result in adequate healing. Finally, the use of antibiotics postoperatively dramatically decreases the incidence of fever and acute cellulites. In a word, it can be concluded that the modified operative modality may facilitate the wound healing and decrease the postoperative complications.

With the combination of multiple treatment, such as: radiotherapy, chemotherapy, even target and imunotherapy, there is a promising trend toward a much conservative approach to curing the primary tumor and groin nodes ${ }^{[11,12]}$. Still, Le $A^{[13]}$ found that the video endoscopic inguinal lymphadenectomy (VEIL) technique could effectively decrease the morbidity of groin node dissection. Nevertheless, the potential role of VEIL in decreasing the morbidity associated with complete inguinal-femoral lymphadenectomy, as well as its' reliability needs to be further investigated, which is also underway in our hospital.

\section{Conclusion}

The application of negative drain technique without subcuticular suture during inguinal lymphadenectomy for patients with vulval malignancies could result in significant decrease in the 
occurrence of wound breakdown and good tolerance,and worth promoting.

\section{Declarations}

\section{Ethics approval and consent to participate}

This study obtained approval from the Research Ethics Committee at Shandong Cancer Hospital and Institute (No. 20121210)

\section{Availability of data and materials}

The datasets analyzed during this study are available from the corresponding

author on reasonable requests

\section{Competing interests}

The authors declare that they have no competing interests

Funding: Not applicable

\section{Authors' contributions}

Xiugui Sheng conceived of the study, and participated in its design and coordination and helped to draft the manuscript. Xiaoling Zhang carried out the clinical studies, participated in the assessment of manipulation effect and drafted the manuscript. Naifu Liu participated in the design of the study. Jinlong Chen and Tingting Zhang carried out the data collection and data analyses. Fufeng Gao: Following up patients. All authors read and approved the final manuscript.

\section{Acknowledgements}

We would like to thank Dr.Beihua Kong from Qilu Hospital of Shandong Medical University and Bill Liu from Shandong University of China for their critical reading of the manuscript.

\section{Disclosure}

There are neither commercial interests nor financial and/or commercial support.

\section{References}

1. Zhang $X$, Sheng $X$,Niu J,et al.Sparing of saphenous vein during inguinal lymphadenectomy for vulval malignancies[J]. Gynecologic oncology,2007,105(3):722-726.

2. Walker KF, Day H, Abu J,et al.Do surgical techniques used in groin lymphadenectomy for vulval cancer affect morbidity rates? Int J Gynecol Cancer 2011;21:1495-1499. 
3. Cagney D, Simmons L, O'Leary DP,et al.The Efficacy of Prophylactic Negative Pressure Wound Therapy for Closed Incisions in Breast Surgery: A Systematic Review and Meta-Analysis[J]. World journal of surgery,2020.

4. Siegel RL, Miller KD, Jemal A. Cancer Statistics. 2017. CA Cancer J Clin. 2017;67:7-30.

5. American Cancer Society. Cancer Facts \& Figs. 2018. Atlanta. 2018.

6. Hacker NF, Leuchter RS, Berek JS. et al. Radical vulvectomy and bilateral inguinal lymphadenectomy through separate groin incisions. Obstet Gynecol. 1981;58:574-9.

7. Sedlis A, Homesley H, Bundy BN. et al. Positive groin lymph nodes in superficial squamous cell vulvar cancer. A Gynecologic Oncology Group Study. Am J Obstet Gynecol. 1987;156:1159-64.

8. Gould N, Kamelle S, Tillmanns $T$, et al Predictors of complications after inguinal lymphadenectomy. Gynecol Oncol 2001;82:329-332.

9. Pontre J, Harding J, Chivers P,et al.Do Groin Drains Reduce Postoperative Morbidity in Women Undergoing Inguinofemoral Lymphadenectomy for Vulvar Cancer?Int J Gynecol Cancer 2018;28:183-187.

10. Webster J, Liu Z, Norman G,et al.Negative pressure wound therapy for surgical wounds healing by primary closure[J]. The Cochrane database of systematic reviews,2019.

11. Iwasaka T. Current trends in the management of vulvar carcinoma. Gan To Kagaku Ryoho. 2005;32(8):1121-7.

12. Jackson KS, Fankam EF, Das N, Naik R, Lopes AD, Godfrey KA,et al. Unilateral groin and pelvic irradiation for unilaterally node-positive women with vulval carcinoma. Int J Gynecol Cancer. 2006;16(1):283-7.

13. Le A,XiongJ, Wang Z,et al.Endoscopy-assisted inguinal lymphadenectomy in vulvar cancer[J].Archives of gynecology and obstetrics,2018,297(5):1277-1283.

14. Carlson et al Carlson JW, Kauderer J, Walker JL, et al. A randomised phase III trial of VH fibrin sealant to reduce lymphoedema after inguinal lymph node dissection: a Gynecologic Oncology Group study. Gynecol Oncol. 2008;110:76Y82.

15. Levenback CF, Ali S, Coleman RL. et al. Lymphatic mapping and sentinel lymph node biopsy in women with squamous cell carcinoma of the vulva: a Gynecologic Oncology Group study. J Clin Oncol. 2012;30:3786-91.

16. Oonk MH. van Hemel BM, Hollema $\mathrm{H}$, et al. Size of sentinel-node metastasis and chances of nonsentinel-node involvement and survival in early stage vulvar cancer: results from GROINSS-V, a multicentre observational study. Lancet Oncol 2010;11:646-52.

\section{Figures}




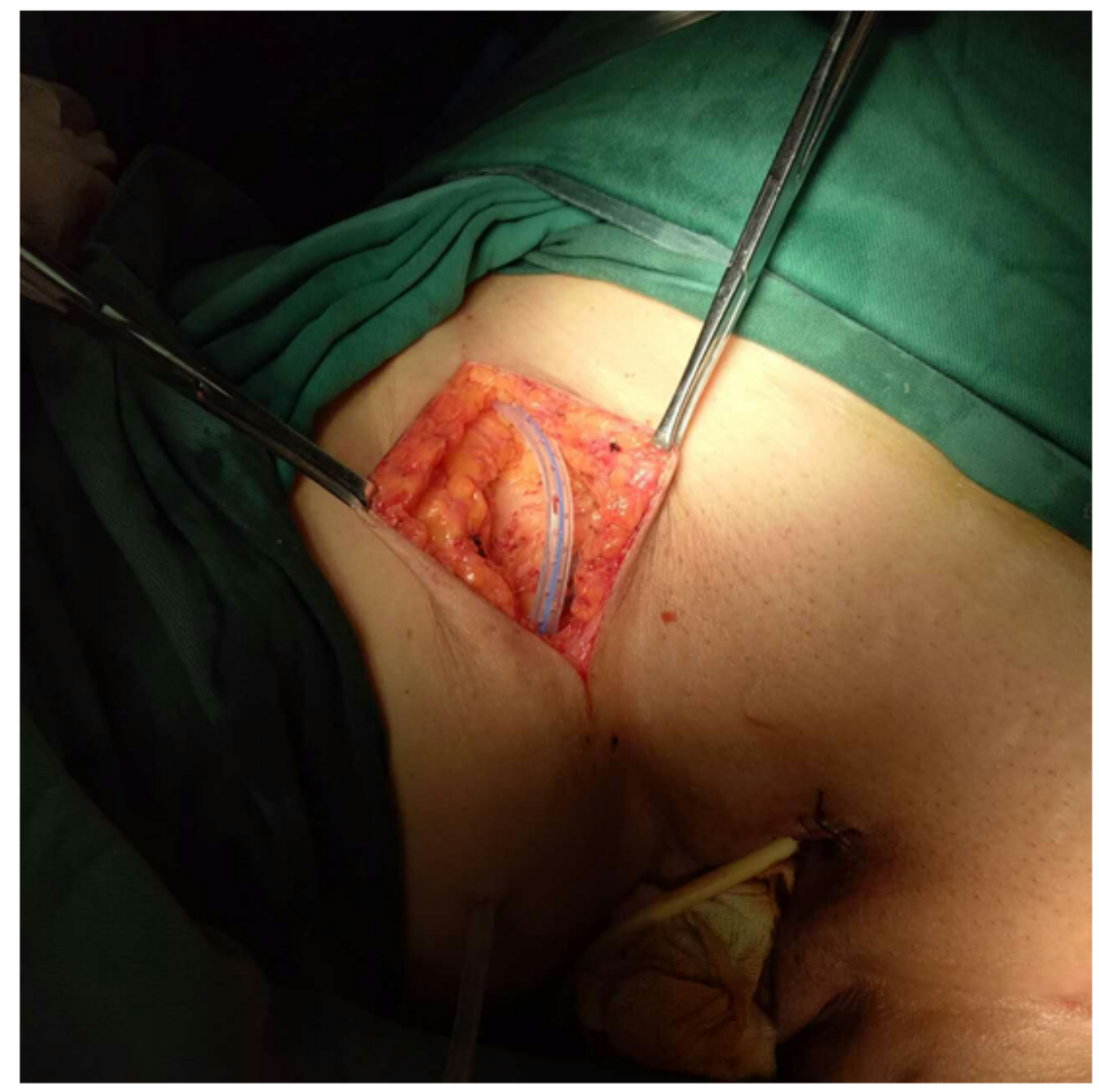

Figure 1

FigA. The flat Fr18(6-mm) drain and the inguinal incision 


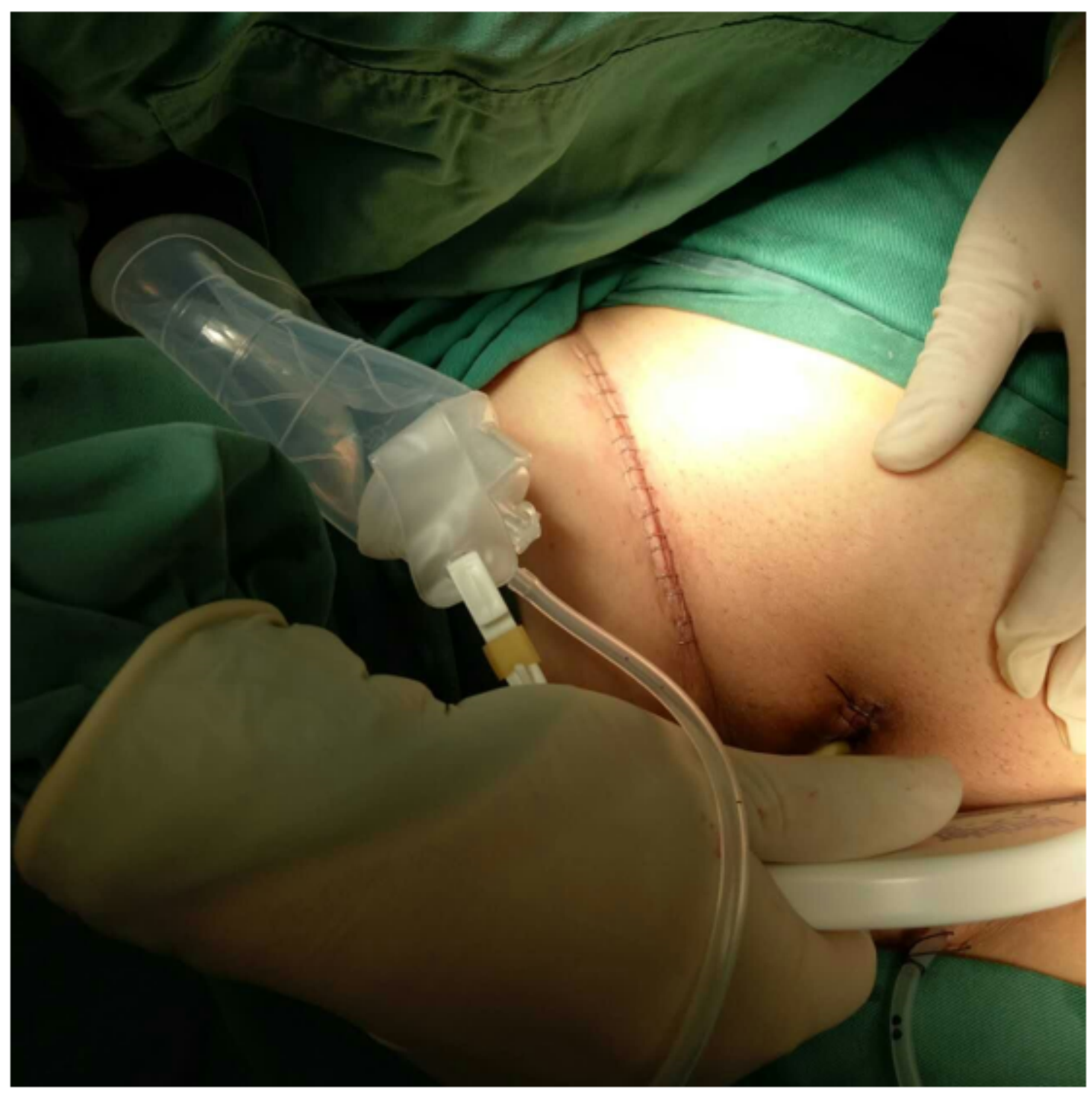

Figure 2

FigB. The drain was secured on the lowest point and connected with the bulb. 